\title{
Give me your password! What are you hiding? Associated factors of intimate partner violence through technological abuse
}

\author{
Alexandra Maftei $^{1}$ (D) Oana Dănilă ${ }^{1}$ \\ Accepted: 4 August 2021 \\ (C) The Author(s), under exclusive licence to Springer Science+Business Media, LLC, part of Springer Nature 2021
}

\begin{abstract}
The present study explored the associated factors of intimate partner violence through technological abuse (ITPV) in a sample of 1113 participants aged 18 to 65 (71.3\% females). Our research's primary questions were the following: 1$)$. Is there a significant link between relationship attachment styles and ITPV perpetration or victimization?; 2). Is there a significant link between participants' demographic and relationship characteristics (i.e., relationship length and partners' fidelity), online behavior (i.e., benign and toxic disinhibition), moral disengagement, psychological distress), and ITPV perpetration or victimization?; and 3). Did the COVID-19 pandemic increase ITPV perpetration or victimization?. We analyzed our data by creating three different groups, depending on participants' answers concerning ITPV, i.e., the overall sample, abusers' and victims' groups. Our main results suggested significant, positive correlations between ITPV perpetration and victimization, moral disengagement, psychological distress, and online disinhibition. Age negatively correlated with IPVT victimization and perpetration. We also found significant associations between participants' dominant relationship attachment style and their own and partners' cheating behavior, as well as ITPV-victimization and perpetration. Finally, $13.7 \%$ to $23 \%$ of participants in all three groups considered that the Covid-19 increased the frequency of ITPV behaviors (for both abusers and victims). Results are discussed considering their theoretical and practical implications for domestic violence and the potential related prevention and intervention strategies.
\end{abstract}

Keywords Domestic violence $\cdot$ Technological abuse $\cdot$ Attachment styles $\cdot$ Psychological distress $\cdot$ Online disinhibition $\cdot$ Moral disengagement

\section{Introduction}

Undoubtedly, domestic violence, i.e., abusive behaviors towards partners, children, and other family members, is a worldwide phenomenon, affecting millions of people every year (Huecker et al., 2021). Intimate partner violence refers to these abusive behaviors within a relationship, and it seems to affect both men and women (Kolbe \& Büttner, 2020). Generally, research suggests that intimate partner violence affects women more than men (Chisholm et al., 2017). Addressing this topic involves various sensitive variables, gender amongst all inducing some of the most intense debates. For example, data generally suggest that

Alexandra Maftei

psihologamaftei@gmail.com

Oana Dănilă

danila.oana@uaic.ro

1 Faculty of Psychology and Education Sciences, Alexandru Ioan Cuza University of Iași, 3 Toma Cozma Street, Iasi, Romania
15-71\% of women might experience intimate partner violence (Lutgendorf, 2019), while the prevalence rates among men vary between $3.4 \%$ to $20.3 \%$ (Kolbe \& Büttner, 2020). However, research on self-reported perpetration suggests greater equality between the sexes (e.g., Desmarais et al., 2012; Muller et al., 2009; Straus, 2009). Also, a significant number of cases remain unreported, given that, compared to any other form of violence, victims of domestic violence are less likely to report their victimization, especially in the case of male victims (Felson et al., 2002).

The wide range of intimate partner violence forms might include, among others, physical, emotional or psychological, sexual, or economic violence (Huecker et al., 2021). These violent intimate behaviors might appear in the offline and online environment (e.g., cyber-abuse; Taylor \& Xia, 2018), and some of the common reasons lying behind these behaviors are related to abusers' need for control due to jealousy, personality, or psychological disorders, low self-esteem, low emotional control and anger management, cultural beliefs, infidelity, or feelings of inferiority (Huecker et al., 2021; Nemeth et al., 2012; Pichon et al., 2020). 
Technology plays a significant role in today's intimate partnerships. We might meet our future husband or wife online, and we can communicate fast and efficiently, share pictures, and generally stay connected to our loved ones. However, the dark side of digital technologies within relationships might include stalking and the surveillance of victims by abusive partners using digital location services (Southworth et al., 2007), monitoring the partners' social networking activity and their e-mails through stolen password, remote cameras and microphones, spyware, or simply by forcing them to reveal their passwords and "share" their accounts (Clevenger \& Gilliam, 2020; Freed et al., 2017; Shimizu, 2013; Southworth et al., 2007).

Technological intimate partner violence or cyber-abuse, an emerging trend in intimate partner violence (Woodlock, 2016), was explored in an increasing number of studies that generally emphasized its adverse psychological consequences. For example, Wolford-Clevenger et al. (2016) suggested an overall prevalence of around $40 \%$, with no differences between men and women in their victimization. The related data from the World Health Organization (WHO, 2017) suggested that the intimate partner violence prevalence against women ranges from $24.6 \%$ in Europe and $29.8 \%$ in the United States. More recent data reported similar prevalence rates, i.e., Toplu-Demirtaş et al. (2020). In Romania, a post-communist European country where $60 \%$ of its citizens consider domestic violence as "normal" and justified behavior (BBC, 2017), a cyber-domestic violence case brought the country a conviction from the European Court of Human Rights in 2020. More specifically, the Romanian court was sanctioned for not investigating a victim's complaint concerning her partner's cyber-abuse; the prosecutor's office closed the case because the threat was considered to be not severe enough, i.e., the complaint about a breach of secrecy of correspondence was considered to be made too late. In this specific context, the European Court of Human Rights' decision clarified that cyber-violence is recognized as a dimension of violence against Romanian women (similar to those in other countries).

Toplu-Demirtaş et al. (2020) also highlighted the significant link between cyber dating abuse victimization and depression. In their systematic review concerning cyber partner abuse, Taylor and Xia (2018) found that 1) overall, frequency rates of victimization varied between $1.1 \%$ to $77.1 \%$; 2) frequency rates of perpetration ranged from $1.8 \%$ to $90.3 \%$; 3) most studies found significant related gender differences; for example, some studies reported higher victimization rates among males (e.g., Bennett et al., 2011), while other reported higher rates among females (e.g., Dick et al., 2014). Concerning cyber perpetration, Burke et al. (2011) reported that females were more likely to monitor their partners using technological means, while Dick et al. (2014) suggested that boys were more likely to contact their partner to determine their location and companionship. However, these findings might also have been biased by the different measures that the authors have used (Zweig et al., 2013).
The consequences of cyber abusive behaviors for both victims and perpetrators seem to be associated with other risk behaviors, such as unprotected sexual relationships with a high number of partners (Dick et al., 2014; van Ouytsel et al., 2016), binge drinking (van Ouytsel et al., 2016), or delinquent behavior (Zweig et al., 2014). In addition, technological abuse is a risk factor for other domestic violence forms, such as physical, sexual, or even homicide (Marganski \& Melander, 2015; Scott et al., 2010). Mcfarlane et al. (2002) suggested, for example, that among the most frequent stalking behaviors before homicide were spying and victim surveillance. Technology provides abusers a quick and easy method to harass their partners, even when they are not physically close, using social media, GPS tracking, constant texting or sexting, and other related forms of intimidation, embarrassment, and control (Melander, 2010; Woodlock, 2016).

The outcomes of intimate partner violence include physical consequences (e.g., fibromyalgia, fractures, bruises, chronic pain, disability), psychological and behavioral outcomes (e.g., substance abuse, shame and guilt feelings, phobias, post-traumatic stress, self-harm, suicidal behaviors, stress disorders), sexual and reproductive consequences (e.g., infertility, pelvic inflammation, unsafe abortions and unwanted pregnancies, gynecological disorders or sexually transmitted infections), and even fatal outcomes, such as homicide, suicide, or maternal mortality (Lafta, 2008).

There are several documented risk factors related to both the perpetrators and victims of intimate partner violence. Common risk factors associated with perpetrators' intimate partner violence include substance abuse, lower education, childhood abuse (Huecker et al., 2021), prior relationship aggression, higher levels of hostility and aggression, mood disorders, stress, depression, psychological distress (Riggs et al., 2000), anxiety (Kivisto, 2014), anxious or dismissive attachment styles (Bond \& Bond, 2004; Goldenson et al., 2007).

\section{Technological Intimate Partner Violence and Online Disinhibition}

Online disinhibition (i.e., "a type of behavior that is not constrained or restrained, implying a reduction in concerns for self-representation and the judgment of others"; Udris, 2014 , p. 254) seems to have a significant role in technological domestic violence. We already know from previous research people who use electronic communication (i.e., technological forms) tend to be less inhibited within their online interactions (Chisholm, 2006). This means that, in their online interaction, they usually communicate things that they would not typically share in real life (Suler, 2004). Thus, the internet and technological ways of communicating, in general, are significantly important for people who have difficulties expressing their feelings, are extremely shy, or have other similar difficulties that the online environment seems to diminish and facilitate 
self-disclosure or altruistic behaviors. Nevertheless, these mediated communication forms might also trigger toxic disinhibition by increasing hostility through decreased intimacy and ignoring social clues (Baym, 2010).

There are six factors of online communication that might facilitate positive (benign disinhibition, which promotes openness, kindness, and generosity) and negative (toxic) online disinhibition (involving rude language, threats), according to Suler (2004): dissociative anonymity (i.e., the online environment facilitates one's ability to separate online behavior from in-person identity), invisibility (one's physical features, such as tone or body language remain hidden, thus lower inhibition), asynchronicity (distorted time flow: communicating online also means that one can avoid and delay the receiver's response, due to the fact that communication doesn't always happen in real-time), solipsistic introjection (one might create the other's character based on their own projections since inperson cues are missing), dissociative imagination (the Internet might be viewed as one's personal fantasy), and minimization of status and authority (the Internet is viewed as an equal "playground", lacking social cues related to authority) (Hellevik, 2019; Udris, 2014). Consistent previous data suggested the significant link between online disinhibition and online deviant behavior (e.g., Hinduja \& Patchin, 2009; Wachs et al., 2019). A recent study exploring technologyrelated perpetration factors and overlap with in-person intimate partner violence conducted by Duerksen and Woodin (2019) suggested that online disinhibition was a significant predictor of technological abuse.

\section{Moral Disengagement}

Moral disengagement occurs when people begin to say, for example, that violence is excusable. More specifically, as Moore (2015) synthesized, "mechanisms of moral disengagement decouple our internal standards from how we construe our behavior, rendering them ineffective" (p. 199). Convincing ourselves that aggression is justifiable, we disengage or ignore the moral standards that prevent violence in everyday life. According to the moral disengagement framework, when moral restraints are removed, regular," good" people may be capable of atrocities, engaging in violent behaviors without experiencing subsequent attendant distress. Studies of individual and group violence have shown that moral disengagement strongly influences our desire to cause others' suffering (Paciello et al., 2008).

Bandura (2002) identified eight primary moral disengagement mechanisms (i.e., moral justification, euphemistic labeling, advantageous comparison, displacement of responsibility, diffusion of responsibility, disregard or distortion of consequences, and dehumanization), which have been studied extensively given the fertile research ground they provide. According to their theory, moral justification (i.e., when "pernicious conduct is made personally and socially acceptable by portraying it as serving socially worthy or moral purposes"; Bandura, 2002, p. 103) is used when violence is rationalized by reference to "rights" or needs that attribute social and moral purposes to harmful actions; for example, one could consider that is acceptable to hurt someone to protect another person's honor. Euphemistic labeling refers to the use of "sanitary language" to make harmful conduct seem less immoral. For example, instead of "rape," one might use euphemistic labeling such as "sexual intercourse without their consent". Finally, advantageous comparison exploits the contrasts between other (significantly more) harmful behaviors and the current immoral ones. For example, one could say, "Checking my partner's e-mails without their consent is nothing comparing to what other partners do, such as cheating or lying."

When using the displacement or diffusion of responsibility, people morally disengage by minimizing their role in harmful actions (e.g., "I slapped a colleague because another member of the group told me to") or obscuring personal agency ("everyone was doing it, so I did it, too). Distortion of Consequences describes the mechanisms through which individuals minimize or disregard the consequences of their harmful actions; as Bandura (2002) suggests, "As long as the harmful results of one's conduct are ignored, minimized, distorted or disbelieved, there is little reason for self-censure to be activated" (p. 108). Finally, dehumanization refers to the situations when perpetrators consider the victims as lacking humanity: "self-censure for cruel conduct can be disengaged or blunted by stripping people of human qualities. Once dehumanized, they are no longer viewed as persons with feelings, hopes, and concerns but as sub-human objects" (Bandura, 2002, p. 109). For example, people are not "individuals," "persons," "humans," but, instead, are called "warms," "degenerates," and other similar dehumanizing terms.

Though moral disengagement has been rarely explored in specific domestic violence contexts, many findings point out the significant link between moral disengagement mechanisms and generally aggressive behavior (which, implicitly, might also appear in intimate relationships). For example, researchers suggested significant links between moral disengagement mechanisms and bullying and cyberbullying perpetration (Runions \& Bak, 2015; Teng et al., 2020), unethical relational behavior such as the likelihood of making false allegations or retaliating against one's partner (Clemente et al., 2019), dating violence and victimization (Cuadrado-Gordillo et al., 2020), deviant peer affiliation (Wang et al., 2020), violent extremism (Blanco et al., 2020), sexist attitudes (SánchezJiménez \& Muñoz-Fernández, 2021), and - generally - antisocial behavior (Risser \& Eckert, 2016; Sijtsema et al., 2019).

\section{Attachment Styles and Intimate Partner Violence}

Attachment, the special bond and the lasting relationships that humans develop from" the cradle to the grave" (Bowlby, 1982, p.127), represents an entire system that gets activated 
when danger is perceived with the primary psychological function of restoring safety. Attachment drives the regulation of emotions through the child's expectations (internal working models) about the caregiver's behavior and availability, either physical or emotional (Bowlby, 1982), resulting in patterns being carried on to the adult romantic relationships. Studies have further focused on delineating a set of clusters, i.e., attachment styles, that encompass specific characteristics of people that succeed to restore safety in efficient, suited terms (i.e., the securely attached people), compared to people that generally struggle to regulate their emotions, either hyper or hypo-activating their attachment system and usually ending up feeling insecurely attached (anxiously or avoidant).

The importance of participants' romantic attachment styles concerning intimate partner violence has been explored in a growing number of studies. For example, researchers have found that "the "mispairing" of an avoidant male partner with an anxious female partner was associated with both male and female violence" (Doumas et al., 2008, p. 616). Other studies suggested that male partners' anxious and avoidant attachment style significantly predicted emotional manipulation, coercive and threat tactics (He \& Tsang, 2014). One recent systematic review conducted by Spencer et al. (2021) points the following main leads: 1) anxious attachment is one of the most robust correlates for both intimate partner violence victimization and perpetration for both genders, and what is more surprising, anxious attachment is significantly more associated than secure attachment; 2) the need to further explore the apparent gender difference reported by studies published so far, asserting that avoidant attachment is a significantly more robust correlate for intimate female partner violent victimization compared to male intimate partner victimization. As such, Slootmaeckers and Migerode $(2018,2020)$ argue that from the attachment perspective, aggression can serve both purposes, either proximity seeking (the dominant strategy of anxiously attached) or distance seeking (avoidant strategy), irrespective of gender.

A systematic review concerning the link between intimate partner violence and attachment styles conducted by Velotti et al. (2018) suggested (in addition to the need for further investigations in the area) that 1) sexual perpetrators are not only generally anxious but also avoidant, and 2) violent behaviors towards one's intimate partner may be one of the regulation strategies used by anxious individuals when feeling frustrated; 3) intimate partner violence victimization and perpetration (using physical, emotional, and sexual violence) are more common among people with an avoidant attachment style. Additionally, among the common risk factors associated with perpetrators' intimate partner violence, the anxious or dismissive attachment styles have also been identified in a series of previous studies (e.g., Bond \& Bond, 2004; Goldenson et al., 2007).
A separate inquiry line derived from the attachment theory and relevant to the current study framework regards the experience of infidelity defined as an attachment injury (AI). Specific relational incidents where one partner violates the expectation that she/he will offer comfort and caring at a particular moment of urgent need (Johnson et al., 2001; Brubacher, 2018), attachment injuries can encompass a variety of breaches of trust and safety in the relationship, that tend to resurface whenever the relations are in danger. Infidelity, a diverse and controversial concept, can take even more complicated subtypes regarding online behaviors (cybersex, sex texting, exchanging pictures, videos with sexual depictions). For the current study, we consider the overall experience of exposure to infidelity as a source of relational injury testing if it aggravates the use of IPV.

As studies specifically exploring online IPV and attachment are scarce, we consider it critical to further investigate whether intimate online partner violence patterns might allow a rapid switch in-between the perpetrators' and victims' roles due to the above-discussed disinhibition. In addition, this specific attachment framework might allow us to understand the underlying dynamics within this link, as in their desperate attempt to restore the emotional connection, partners end up injuring (including being unfaithful) each other more quickly as they might feel more "protected" by the screens.

\section{The Present Study}

Previous research suggested significant links between online moral disengagement and cyber aggression (Runions \& Bak, 2015), dating violence and victimization (Cuadrado-Gordillo et al., 2020), and general deviant relationship behaviors (Clemente et al., 2019). Additionally, the relationship between attachment styles, toxic online disinhibition, and several forms of intimate partner violence, including cyber-abuse, was suggested by a growing number of studies (e.g., Duerksen \& Woodin, 2019; Hellevik, 2019; Velotti et al., 2018). Based on these findings and other related results that emphasized the significant role of various demographical variables when exploring technological abuse in intimate relationships, such as gender, age, or fidelity (e.g., Nemeth et al., 2012; Velotti et al., 2018), our primary aims was to explore technological abuse as an intimate partner violence form. More specifically, we aimed to investigate how attachment styles, anxiety, depression, stress, online disinhibition, and moral disengagement relate to technological intimate partner violence, in addition to a series of demographic variables (age, gender, relationship length, fidelity).

Notably, we aimed to explore these links in both victims and perpetrators of technological intimate partner violence (ITPV) and assess the potential links between them for a more comprehensive view. More importantly, to also address the 
potential exacerbation of these behaviors due to the COVID19 pandemic, since several studies have already pointed out the pandemic adverse effects related to the increasing rates of various forms of intimate partner violence (e.g., Evans et al., 2020; Viero et al., 2021).

Our research's primary questions and assumptions were the following:

1. Is there a significant link between relationship attachment styles and proneness to technological intimate partner perpetration or victimization? According to the previous studies in the area, we assumed that anxious or dismissive attachment styles would be associated with intimate cyber abuse or victimization (e.g., Bond \& Bond, 2004; Goldenson et al., 2007). More specifically, participants with dominant anxious and dismissive attachment styles would report more frequent experiences related to intimate cyber-abuse and victimization.

2. Is there a significant link between participants' demographic and relationship characteristics (i.e., relationship length and partners' fidelity), online behavior (i.e., benign and toxic disinhibition), moral disengagement, psychological distress (i.e., depression, anxiety, and stress), and proneness to technological intimate partner perpetration or victimization? Given the previous findings, we assumed significant and positive relationship between these variables. More specifically, we assumed that higher levels of moral disengagement and toxic disinhibition, as well as previous infidelity experiences, would be associated with proneness to technological intimate partner perpetration. At the same time, we assumed that psychological distress would be linked to both technological intimate partner perpetration and victimization. Given that previous research reported mixed findings related to gender differences in IPPV perpetration and victimization (e.g., Bennett et al., 2011; Burke et al., 2011; Dick et al., 2014), we expected our related findings to shed more light on these potential gender differences.

3. Did the COVID-19 pandemic increase technological intimate partner abuse? Given the potential psychological distress of the current health crises and the increased number of hours spent online, we consider that most potential victims of ITPV would consider that these abusive episodes increased since the pandemic outbreak.

\section{Research Procedure and Materials}

The study was designed and ran following the Helsinki Declaration ethical guidelines and the ethical research requirements approved by the institutional board from the institution where the author is affiliated. The participants provided informed consent to participate in this study. Participants answered an online, anonymous survey, and the time needed to answer the questions was about twenty-five minutes. The survey link was made available in several student online forums (mostly related to the Romanian university where the authors are affiliated), as well as other connected social media groups. No rewards were offered for participation. Following the study's completion, participants were given a debriefing form and the contact details from a psychotherapist (which would have counseled the participants with no charges involved) in case they experienced distress during data collection; however, no such cases were reported. Data collection took place one year after the COVID-19 breakout.

\section{Participants}

Our initial sample consisted of 1129 participants. Eight participants were removed following the completion of the Relationship Style Questionnaire (RSQ; Griffin \& Bartholomew, 1994), because they reported identical relationship attachment style patterns. Another six participants were removed from the final sample because they did not fit one of the two primary conditions to participate in the study: 1) age over $18 ; 2$ ) all participants had to be in a relationship older than or equal to six months old. Thus, our final sample consisted of 1113 participants aged 18 to $65(M=24.48$, $S D=7.90)$. Most participants were females $(71.3 \%)$ and in a relationship for at least three years $(37.4 \%)$. All participation was voluntary. Participants were informed that there were no right or wrong answers to the scales' questions and that their answers would remain completely anonymous and confidential. Also, participants were informed that they could retire from the study at any time.

\section{Instruments}

The dependent variable, technological intimate partner violence, was measured using the Cyber Aggression in Relationships Scale (CARS; Watkins et al., 2016), also used by Duerksen and Woodin (2019) when exploring this variable. CARS contains 18 items that measure perpetration. We chose this scale due to its focus on technological partner abuse, which shaped the primary research aim of the current paper and its psychometric proprieties previously assessed in studies with a similar research focus (e.g., Nacar et al., 2021). Also, CARS measures cyber aggression and victimization similarly for women and men, which was also an important criterion for us when choosing this particular scale. We used its original form to measure technological intimate partner violence perpetration in the last six months and added the scale's victimization-version. Therefore, participants answered 36 items that measured both perpetration (18 items) and victimization (18). Example items include "I checked my partner's e-mail account to see whom they were talking to or 
e-mailing without their permission" (perpetration), and "My partner checked my e-mail account to see whom I was talking to or e-mailing without my permission" (victimization). Participants answered each item by referring to the frequency these behaviors have happened in their relationship in the past six months, on a scale ranging from 0 to $7: 0=$ it has never happened since we are together, not necessarily in the last six months; $1=$ this never happened in the last six months; $2=$ it happened once in the last six months; $3=$ it happened twice in the last six months; $4=$ it happened $3-5$ times in the last six months; $5=$ it happened 6-10 times in the last six months; $6=$ it happened 11-20 times in the last six months; $7=$ this happened more than 20 times in the past six months.

Additionally, we added two questions aimed to investigate whether these behaviors intensified during the pandemic, i.e., "All of these personal behaviors - previously described (behaviors that describe facts/events in my relationship) intensified during the COVID-19 pandemic, compared to the period before COVID-19 pandemic" (this question followed the perpetrator version of CARS) / "All of these behaviors - my partners' behaviors - previously described (behaviors that describe facts/events in my relationship) intensified during the COVID-19 pandemic, compared to the period before COVID19 pandemic" (this question followed the victim version of CARS). Participants had three options to answer these two additional CARS items: Yes/ No / My relationship is not that old to make such comparisons. Higher scores indicated higher levels of ITPV perpetration or victimization. Cronbach's alpha indicated good reliability for both forms of the scale (CARS - aggressor: $\alpha=.916$; victim: $\alpha=.920$ ).

We used the Relationship Style Questionnaire (RSQ; Griffin \& Bartholomew, 1994), a scale aiming to assess participants' romantic attachment styles. We chose this scale due to its proven reliable psychometric properties in various cultural contexts and age groups (e.g., Guédeney et al., 2010), and, more importantly, its wide use in research exploring the links between attachment styles and domestic violence (e.g., Johnson, 2006). Participants answered the 30 items on a scale ranging from 1 (totally disagree) to 5 (totally agree). Their answers were then used to create a composite score for each of the four attachment style subscales, i.e., secure, fearful, preoccupied, and dismissing. Example items include "I find it difficult to trust others completely" (fearful); "It is very important to me to feel independent" (dismissing), "I find it easy to get emotionally close to others" (secure), and "I worry that others don't value me as much as I value them" (preoccupied). In the present study, we calculated participants' average scores on each dimension and considered the primary (i.e., dominant) attachment style as the scale with the highest score. To avoid any confusion, we removed any participants with identical scores on the four potential dominant styles $(N=6)$. Our decision to remove these participants was based on the idea that we aimed to identify each participant's dominant style and create separate groups, depending on these attachment patterns, subsequently linking them to the other variables in our research. More importantly, in the cases where participants obtained the highest possible score on each dimension, we considered that their answers were most likely unreliable, and we decided to exclude them to ensure the accuracy of our data.

We further used the self-reported Depression, Anxiety and Stress Scale - 21 Items (DASS-21; Lovibond \& Lovibond, 1995) to measure a) depression, i.e., dysphoria, hopelessness, devaluation of life, self-deprecation, lack of interest/involvement, anhedonia, and inertia; b) autonomic arousal, skeletal muscle effects, situational anxiety, and subjective experience of anxious affect (anxiety), and c) stress levels of chronic nonspecific arousal. In addition, it assesses difficulty relaxing, nervous arousal, and being easily upset/agitated, irritable / over-reactive, and impatient. We chose this scale for its proven reliable psychometric properties over time, its efficiency (i.e., a relatively small number of items measuring three psychological dimensions), and its consistent use in research examining domestic violence (e.g., Cheung et al., 2019), including intimate partner violence during the pandemic (e.g., Sediri et al., 2020). Participants answered the items ( 7 items for each subscale) considering how much the statements applied to them considering the past week, on a scale ranging from 0 (did not apply to me at all) to 3 (applied to me very much or most of the time). Example items include "I found it difficult to work up the initiative to do things (depression); "I was worried about situations in which I might panic and make a fool of myself" (anxiety); "I was intolerant of anything that kept me from getting on with what I was doing" (stress). Cronbach's alpha indicated good reliability for each dimension of the scale, anxiety: $\alpha=.878$, depression: $\alpha=.891$, and stress: $\alpha=.874$. Higher scores on each subscale indicated higher levels of depression, anxiety, and stress.

The Online Disinhibition Scale (Udris, 2014) measured participants' lack of inhibition within the online environment. The scale comprises 11 items assessing two primary factors, i.e., benign disinhibition (example item: "The Internet is anonymous, so it is easier for me to express my true feelings or thoughts"), and toxic disinhibition (Example item: "I don't mind writing insulting things about others online, because it's anonymous"). In addition to its reliability, we chose this particular scale given its previous, significant use in other studies that explored technology-related in-person intimate partner violence (Duerksen \& Woodin, 2019; Wachs et al., 2019). Participants answered on a scale ranging from 0 (disagree) to 3 (agree). Cronbach's alpha indicated good reliability for each of the two subscales: $\alpha=.846$ for benign disinhibition and $\alpha=.813$ for toxic disinhibition.

Finally, we used the Moral Disengagement Scale (Bandura et al., 1996) to explore the potential cognitive mechanisms underlying participants' unethical behavior. The scale 
assesses eight possible mechanisms, namely Moral justification ("It is all right to fight to protect your friends"), Euphemistic language ("Slapping and shoving someone is just a way of joking"), Advantageous comparison ("Damaging some property is no big deal when you consider that others are beating other people up"), Displacement of responsibility("If kids are living under bad conditions they cannot be blamed for behaving aggressively"), Diffusion of responsibility ("A kid in a gang should not be blamed for the trouble the gang causes"), Distorting consequences ("It is okay to tell small lies because they don't really do any harm"), Attribution of blame ("If kids fight and misbehave in school it is their teacher's fault"), dehumanization ("Some people deserve to be treated like animals"). We used this scale due to its wide use in assessing moral disengagement in various cultural contexts and age groups, including several samples from Romania, and, more importantly, due to the significant number of studies that assessed moral disengagement using this scale, when examining the links to domestic violence, attachment styles, and aggressive behavior, in general (e.g., D'Urso et al., 2018; Maftei \& Holman, 2020). Participants answered on a 3-point Likert scale ranging from 0 (disagree) to 2 (agree). We computed a total score for moral disengagement, and Cronbach's alpha indicated good reliability for the scale, $\alpha=.928$.

All instruments were self-reported. We ran a pretesting procedure in a similar sample of adults $(M=28.4, S D=$ 1.25 ) to assess the potential difficulties of the scales we used. No issues were reported during this procedure. We used a demographic scale to assess participants' age, gender, type, and relationship length (marriage, domestic partnership). We also added a series of question related to participants' and their partners' infidelity (In the current relationship, there have been episodes of infidelity on my part, which my partner knows about (Yes/No); In the current relationship, there have been episodes of infidelity on my part, which my partner does not know about (Yes/No); In the current relationship, there have been episodes of infidelity on the part of my partner (Yes/No).

\section{Results}

The present study used a non-experimental cross-sectional data research design. We used the SPSS (v. 24) program to analyze the data, and there was no missing data within the collected answers. Table 1 provides the descriptive statistics for the participants in our study. We reported these values for both the entire sample $(N=1113)$, as well as for participants who scored higher than 18 (total score) on each of the two scales (CARS- aggressor's form, and CARS -victim's form). We chose to do that since the possible answers for CARS included two answers that indicated no potential cyberaggressive behaviors. More specifically, participants answered
Table 1 Descriptive statistics for the participants

\begin{tabular}{|c|c|c|c|}
\hline Overall sample $(N=1113)$ & $M$ & \multicolumn{2}{|l|}{$S D$} \\
\hline Age & 24.48 & 7.90 & \\
\hline Gender & $N$ & & $\%$ \\
\hline male & 319 & & 28.7 \\
\hline female & 794 & & 71.3 \\
\hline Relationship length & $N$ & & $\%$ \\
\hline 6 moths -1 year & 318 & & 28.6 \\
\hline $1-3$ years & 379 & & 34.1 \\
\hline$>3$ years & 416 & & 37.4 \\
\hline Relationship attachment style & $N$ & & $\%$ \\
\hline secure & 181 & & 16.3 \\
\hline anxious & 113 & & 10.2 \\
\hline dismissing & 620 & & 55.7 \\
\hline fearful & 199 & & 17.9 \\
\hline Fidelity & Yes & & No \\
\hline Own and known (by partner) infidelity & \multicolumn{2}{|c|}{$106(9.5 \%)$} & $1007(90.5 \%)$ \\
\hline Own and unknown (by partner) infidelity & \multicolumn{2}{|c|}{$98(8.8 \%)$} & $1015(91.2 \%)$ \\
\hline Partner's infidelity & \multicolumn{2}{|c|}{$146(13.1 \%)$} & $967(86.9 \%)$ \\
\hline Cyber-aggressors $(N=374)$ & $M$ & $S D$ & \\
\hline Age & 23.23 & 6.46 & \\
\hline Gender & \multicolumn{2}{|l|}{$N$} & $\%$ \\
\hline male & \multicolumn{2}{|l|}{82} & 21.9 \\
\hline female & \multicolumn{2}{|l|}{292} & 78.1 \\
\hline Relationship length & \multicolumn{2}{|l|}{$N$} & $\%$ \\
\hline 6 moths -1 year & \multicolumn{2}{|l|}{125} & 33.4 \\
\hline $1-3$ years & \multicolumn{2}{|l|}{128} & 34.2 \\
\hline$>3$ years & \multicolumn{2}{|l|}{121} & 32.4 \\
\hline Relationship attachment style & \multicolumn{2}{|l|}{$N$} & $\%$ \\
\hline secure & \multicolumn{2}{|l|}{64} & 17.1 \\
\hline anxious & \multicolumn{2}{|l|}{43} & 11.5 \\
\hline dismissing & \multicolumn{2}{|l|}{185} & 49.5 \\
\hline fearful & \multicolumn{3}{|l|}{82} \\
\hline Fidelity & \multicolumn{2}{|l|}{ Yes } & No \\
\hline Own and known (by partner) infidelity & \multicolumn{2}{|c|}{$55(14.7 \%)$} & $319(85.3 \%)$ \\
\hline Own and unknown (by partner) infidelity & $53(14$ & $\%)$ & $321(85.8 \%)$ \\
\hline Partner's infidelity & $69(18$. & $\%)$ & $305(81.6 \%)$ \\
\hline Cyber-victims $(N=282)$ & $M$ & $S D$ & \\
\hline Age & 23.18 & 6.25 & \\
\hline Gender & $N$ & & $\%$ \\
\hline male & 74 & & 26.2 \\
\hline female & 208 & & 73.8 \\
\hline Relationship length & $N$ & & $\%$ \\
\hline 6 moths -1 year & 102 & & 36.2 \\
\hline $1-3$ years & 100 & & 35.5 \\
\hline$>3$ years & 80 & & 28.4 \\
\hline Relationship attachment style & $N$ & & $\%$ \\
\hline secure & 41 & & 14.5 \\
\hline anxious & 34 & & 12.1 \\
\hline dismissing & 137 & & 48.6 \\
\hline fearful & 70 & & 24.8 \\
\hline Fidelity & Yes & & No \\
\hline Own and known (by partner) infidelity & $49(17$. & & $233(82.6 \%)$ \\
\hline Own and unknown (by partner) infidelity & $50(17$. & & $232(82.3 \%)$ \\
\hline Partner's infidelity & $67(23$. & $\%)$ & $215(76.2 \%)$ \\
\hline
\end{tabular}

the scales' items on an 8-point Likert scale, where $0=$ this never happened ever in our relationship, and $1=$ this never happened ever in our relationship in the past six months. Thus, the total scores for participants who reported no cyber perpetration or victimization experiences from their partners in the past six months ranged from 18 to 0 . We considered potential ITPV perpetrators or victims only those who scored higher than 18 
on these two scales (i.e., CARS- aggressor's form, and CARS victim's form). Therefore, we reported the results for three different groups: the overall sample $(N=1113)$, cyber-perpetrators $(N=374)$, and cyber-victims $(N=282)$.

However, we consider it important to clarify a series of factors related to this specific distinction between the groups, i.e., victims and perpetrators. More specifically, it is important to mention that this differentiation was based only on the scores that would indicate that one of the 18 possible behaviors (i.e., behaviors that would indicate potential technological abuse) has happened at least once in the last six months. Thus, though we refer in the following data analyses to "the victims' groups" and "the perpetrators' group", it is essential to keep in mind that lower scores on these two dimensions - cyber-abuse (measured with the CARS scale) might indicate that one of these behaviors happened once.

Preliminary Kolmogorov-Smirnov and Shapiro-Wilk normality tests suggested that our data was not normally distributed. Therefore, we used non-parametric tests to explore our results. We performed these analyses for all the groups (overall sample, perpetrators' and victims' groups) and reported the related gender differences. Table 2 provides the details related to the associations between the main variables.

\section{Correlation Analyses}

In the overall sample, we found a significant, powerful association between ITPV-perpetration and ITPV-victimization: higher levels of ITPV-aggression seemed strongly correlated with victimization experiences. Toxic and benign disinhibition were also positively and significantly correlated with both ITPV perpetration and victimization, as well as all the other explored variables (moral disengagement, anxiety, depression, and stress). Age was also significantly correlated with all the variables in the overall sample. By contrast, this specific association was negative: the lower the ages, the lower participants' ITPV-perpetration, ITPV-victimization, toxic and benign online disinhibition, moral disengagement, depression, anxiety, and stress.

In the perpetrators' group, ITPV-aggression experiences positively and significantly correlated with all the variables, except age. Similarly, ITPV-victimization positively correlated with all the variables, except age. In the victims' group, we found significant, positive correlations between ITPV-victimization and all variables, except age and benign disinhibition. Also, in the victims' group, ITPV-aggression significantly and positively correlated with all the variables, except age.

\section{Gender Differences}

Mann-Whitney test results for the overall sample indicated significant gender differences related to benign and toxic online disinhibition, moral disengagement, anxiety, and stress.
More specifically, female participants in the overall sample scored higher than males at the benign online disinhibition ( $U=116,988, Z=-1.99, p=.04)$; meanwhile, males scored higher at the toxic disinhibition measure $(U=98,979, Z=-$ $6.36, p<.001$ ). In addition, male participants seemed to be more morally disengaged compared to female participants $(U=105,991, Z=-4.26, p<.001)$, while females scored higher on anxiety $(U=109,157, Z=-3.60, p<.001)$ and stress measurements $(U=108,517, Z=-3.74, p<.001)$.

Mann-Whitney test results for the cyber-victims group suggested significant gender differences related to participants' moral disengagement $(U=5577, Z=-3.518, p<.001)$, male participants scoring significantly higher females. We also found significant differences in toxic disinhibition $(U=$ 4681, $Z=-5.206, p<.001$ ), with male participants scoring significantly higher than females.

In the ITPV-perpetrators group, we found significant gender differences concerning participants' scores on CARS-victims' form, moral disengagement, and stress. More specifically, our results suggested that males in the perpetrators' group had significantly higher scores than females on the CARS - victims' form $(U=9352.5, Z=-3.03, p=.002)$. In addition, male participants in the perpetrators' group also seemed more morally disengaged than females $(U=9232, Z=-3.17, p=.002)$ and more stressed $(U=9263.5, Z=-2.718, p=.007)$ than females. Additionally, male participants in the perpetrators' group scored significantly higher than females on the toxic disinhibition dimension $(U=7790.5, Z=-5.167, p<.001)$.

\section{Relationship Attachment Styles}

Overall Sample In the overall sample group, Kruskal-Wallis H test results suggested that there was a statistically significant difference in ITPV perpetrating behaviors between different types of attachment style patterns, $H(3)=18.52, p<.001$, with a mean rank of 576.28 for the secure attachment group, 575.18 for the anxious group, 523.97 for the dismissing group, and 632.06 for the fearful dominant attachment group. Participants with a secure attachment $(M d n=18)$ scored higher than those with anxious attachment styles $(M d n=17)$ and dismissing $(M d n=14)$ attachment patterns, and similar to those with fearful dominant attachment styles $(M d n=18)$. Additionally, Kruskal-Wallis $\mathrm{H}$ tests also suggested that there was a statistically significant difference in cyber-victimization reported behaviors between different types of attachment style patterns, $H(3)=14.60, p=.002$, with a mean rank of 559.98 for the secure attachment group, 583.72 for the anxious group, 529.32 for the dismissing group, and 625.36 for the fearful dominant attachment group. Participants with a secure attachment $(M d n=23)$ scored lower than those with anxious attachment styles $(M d n=25)$, higher than the dismissing group $(M d n=20)$, and similar to those with fearful dominant attachment styles $(M d n=23)$. 


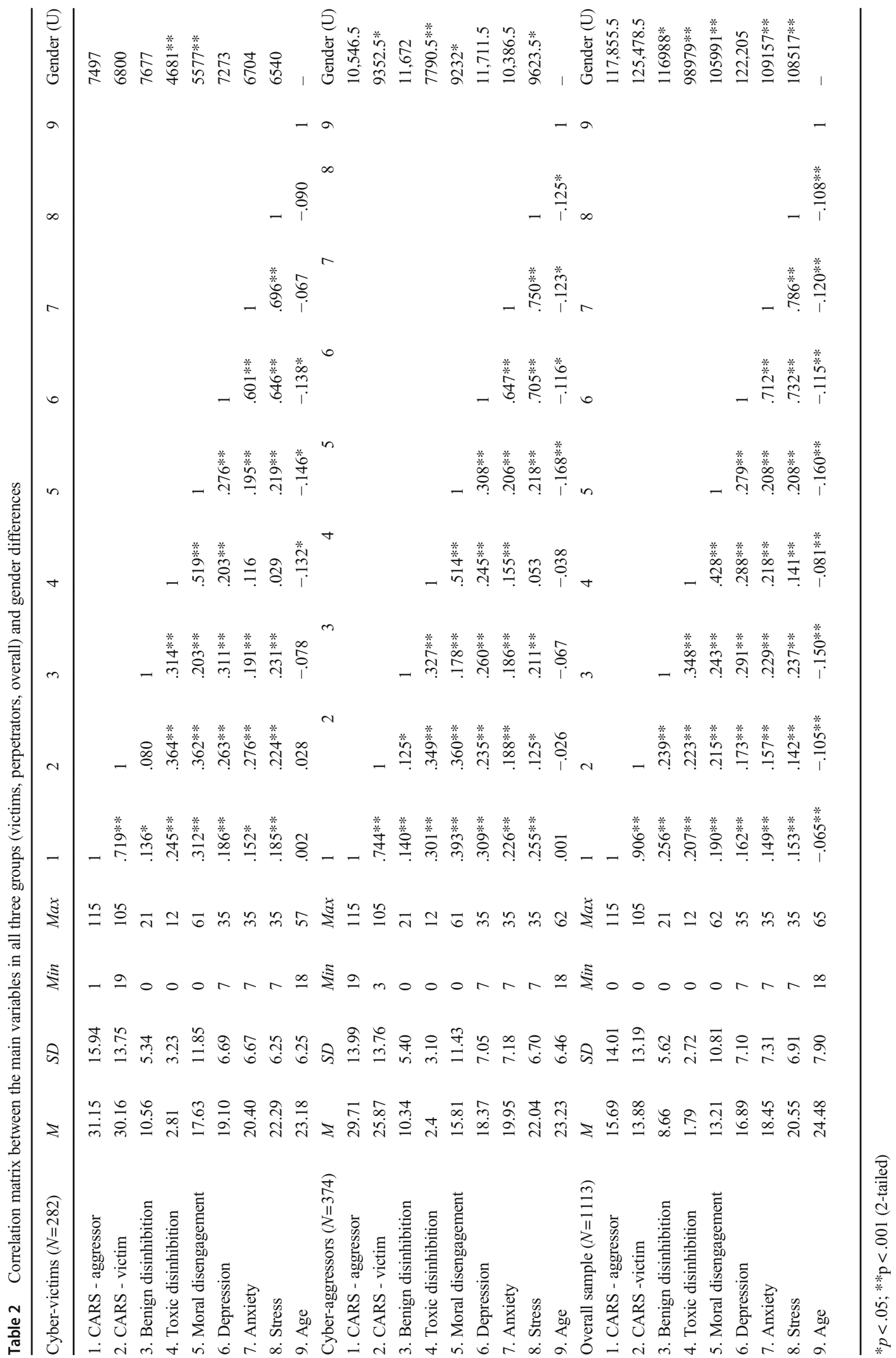


Post-hoc Mann Whitney tests suggested 1) marginally significant differences $(U=50,976, Z=-1.88, p=.06)$ between participants with a dominant secure attachment style versus participants with a dismissing style, with the "secure" group scoring higher than the "dismissing group" on CARSaggression form; 2 ) significant differences ( $U=49,468, Z=$ $4.22, p<.001)$ between participants with a dominant dismissing attachment style and those with a fearful style, "dismissing" participants scoring significantly lower than "fearful" ones at both CARS-aggression and CARSvictimization $(U=50,905, Z=-3.741, p<.001)$ forms.

Perpetrators' Group In the perpetrators' group, KruskalWallis $\mathrm{H}$ test results suggested that there was a marginally significant difference in ITPV -perpetrating behaviors between different types of attachment style patterns, $H(3)$ $=7.54, p=.05$, with a mean rank of 197.91 for the secure attachment group, 214.56 for the anxious group, 172.84 for the dismissing group, and 198.27 for the fearful dominant attachment group. Participants with a secure attachment $(M d n=23)$ scored lower than those with anxious attachment styles $(M d n=25)$, higher than those dismissing $(M d n=20)$, and similar to those with fearful dominant attachment styles $(M d n=23)$. Kruskal-Wallis $\mathrm{H}$ test results suggested no significant difference in ITPV -victimization within the perpetrators' group, $H(3)=6.90, p=.075$. Furthermore, post-hoc Mann Whitney tests suggested significant differences between participants with a dominant anxious style and those with a dismissive style concerning ITPV-perpetration $(U=3067.5$, $Z=-2.34, p=.01$ ), participants in the anxious group scoring significantly higher than those in the dismissing group. We found significant related differences concerning cybervictimization ( $U=3159.5, Z=-2.10, p=.03)$; participants in the anxious group also scored significantly higher than those in the dismissing group. Finally, Mann-Whitney tests suggested significant differences between participants with a dominant dismissing style and those with a fearful style concerning ITPV-victimization $(U=6290, Z=-2.22$, $p=.026)$.

Victims' Group In the victims' group, Kruskal-Wallis $\mathrm{H}$ test results suggested that there was a significant difference in ITPV perpetrating behaviors between different types of attachment style patterns, $H(3)=9.64, p=.02$, with a mean rank of 171.15 for the secure attachment group, 154.35 for the anxious group, 128.75 for the dismissing group, and 142.84 for the fearful dominant attachment group. Participants with a secure attachment $(M d n=32)$ scored higher than those with anxious attachment styles $(M d n=28.5)$, higher than those dismissing $(M d n=25)$, and higher than those with fearful dominant attachment styles $(M d n=26)$.

Post-hoc Mann Whitney tests suggested significant differences between participants with a dominant secure attachment style and those with a dismissing style $(U=1970.5, Z=-2.89$, $p=.004)$ concerning ITPV-perpetration, with higher scores among participants with a secure dominant style. We found the same significant differences concerning these differences (secure versus dismissing) concerning the victimization dimension $(U=1892, Z=-3.17, p=.001)$. We also found significant differences between participants with anxious versus dismissing attachment styles concerning ITPV -victimization ( $U=1817, Z=-1.98, p=.04)$, with "dismissing" participants scoring higher than "anxious" ones.

\section{Dominant Relationship Attachment Style, Cheating, and ITPV}

In the overall group, Chi-square test results suggested a significant association between participants' dominant relationship attachment style and cheating behavior (that the partner knows about), $\chi^{2}=14.79, p=.002$. More specifically, participants with a dismissing style cheated the most, while participants with an anxious dominant style cheated the least. No significant associations were found between the dominant relationship attachment style and "secret" cheating episodes $\left(\chi^{2}=.765, p=.858\right)$. However, we found significant associations with the partner's cheating behavior and participants' dominant relationship attachment style $\left(\chi^{2}=11.71\right.$, $p=.008)$. More specifically, participants with a dominant dismissing attachment style seemed to report the most frequent cheating episodes from their partners, while those with fearful dominant styles reported the least known infidelity behaviors from their partners.

In the ITPV perpetrators' group, Chi-square test results also suggested a significant association between participants' dominant relationship attachment style and cheating behavior (that the partner knows about), $\chi^{2}=12.15, p=.007$, i.e., participants with a dismissing and fearful attachment style cheated the most, while participants with secure and anxious dominant styles cheated the least. No significant associations were found between the dominant relationship attachment style and "secret" cheating episodes $\left(\chi^{2}=.900, p=.825\right)$. However, we found significant associations with the partner's cheating behavior and participants' dominant relationship attachment style $\left(\chi^{2}=22.03, p<.001\right)$. More specifically, participants with dismissing and fearful attachment styles seemed to report the most frequent cheating episodes from their partners, while those with a secure dominant style reported the least known infidelity behaviors from their partners.

Finally, in the ITPV victims' group, Chi-square test results also suggested no significant associations between participants' dominant relationship attachment style and cheating behavior (that the partner knows about), $\chi^{2}=5.74, p=.125$, nor "secret" cheating episodes $\left(\chi^{2}=.329, p=.955\right)$. However, we found significant associations with the partner's cheating behavior and participants' dominant relationship attachment 
style $\left(\chi^{2}=12.02, p=.007\right)$. More specifically, participants with dismissing attachment styles seemed to report the most frequent cheating episodes from their partners, while those with a secure dominant style reported the least known infidelity behaviors from their partners.

\section{The Perceived Impact of the COVID-19 Pandemic}

We asked participants at the end of both forms of the CARS (victimization and perpetration forms) whether they felt that the pandemic had increased the frequency of the behaviors described by the two scales. Participants had to choose between three possible answers, i.e., "yes," "no," and "not the case; we were not together before the pandemic." Results (see Table 3) generally suggested that 1) in the overall sample, $13.7 \%$ of the participants considered that their abusive behaviors increased since the pandemic, and the same percentage considered that their partner's technological abuse also increased since the COVID-19 outbreak; 2) in the victims' group, $17.7 \%$ of the participants considered that their abusive behaviors increased since the pandemic, and $27.7 \%$ considered that their partner's technological abuse also increased since the COVID-19 outbreak; and 3) in the perpetrators' group, $15.8 \%$ of the participants considered that their abusive behaviors increased since the pandemic, while $23 \%$ considered that their partner's technological abuse also increased since the COVID-19 outbreak.

Table 3 The perceived impact of the COVID-19 pandemic on CARS behaviors

\begin{tabular}{llll}
\hline Overall sample $(N=1113)$ & & $N$ & $\%$ \\
\hline CARS-aggressor & No & 756 & 67.9 \\
& Yes & 153 & 13.7 \\
CARS-victim & Not applicable & 203 & 18.2 \\
& No & 757 & 68 \\
& Yes & 153 & 13.7 \\
Victims' group $(N=282)$ & Not applicable & 203 & 18.2 \\
CARS-aggressor & & $N$ & $\%$ \\
& No & 169 & 59.9 \\
& Yes & 50 & 17.7 \\
CARS-victim & Not applicable & 63 & 22.3 \\
& No & 138 & 48.9 \\
& Yes & 78 & 27.7 \\
Perpetrators' group $(N=374)$ & Not applicable & 63 & 22.3 \\
CARS-aggressor & & $N$ & $\%$ \\
& No & 240 & 64.2 \\
& Yes & 59 & 15.8 \\
CARS-victim & Not applicable & 74 & 19.8 \\
& No & 212 & 56.7 \\
& Yes & 86 & 23 \\
& Not applicable & 74 & 19.8 \\
\hline & & & \\
& & & \\
& & &
\end{tabular}

\section{Discussion}

Our research's primary questions and assumptions were related to the potential associations between intimate partner violence through technological perpetration and victimization, relationship attachment styles, participants' demographic and relationship characteristics (i.e., relationship length and partners' fidelity), their online behavior (i.e., benign and toxic disinhibition), moral disengagement, and psychological distress. Additionally, we investigated whether the COVID-19 pandemic increased ITPV perpetration and victimization behaviors. Finally, we analyzed our data by creating three different groups, depending on participants' answers concerning ITPV, i.e., the overall sample, perpetrators' and victims' groups.

Our results suggested that 374 participants $(33.60 \%)$ scored higher than 18 on the perpetrators' form of ITPV measurement (i.e., CARS), and 282 participants scored higher than 18 on the victims' form of CARS. We considered these scores as potential indicators of perpetration or victimization. However, we already mentioned that these scores indicate potential technological abuse or victimization, considering that a higher score $(>18)$ indicated the possibility of one or more related behaviors to occur (from the participants of their partners). Though limited, these results also point out that, in our sample, we had more participants scoring higher on the abusers' form than on the victims' form. Among the 374 participants who scored higher than 18 on the abusers' form of CARS, most of them were females, in long-term relationships (>3 years), with a dismissing dominant relationship attachment style (participants with a dismissing style also reported cheating more, while participants with an anxious dominant style reported the least cheating behaviors). However, though most of them had a dominant dismissing relationship attachment style, participants in the anxious group scored significantly higher on ITPV perpetration than those in the dismissing group.

Additionally, our results also suggested that 282 participants $(25.33 \%)$ scored higher than 18 and met our ITPV victimization criteria. Among these 282 participants, most were females in a less than a year-old relationship, with a dismissing dominant relationship attachment style. Contrary to our expectations, participants from this group with a secure attachment scored higher on ITPV-perpetration than those with any other dominant styles, while "dismissing" participants scoring higher than "anxious" ones on ITPV-victimization. Finally, in the overall sample (primarily females, in longterm, i.e., >3-years old relationships, with a dismissing dominant relationship attachment style), we found the same patterns related to these dominant relationship attachment styles: the "secure" group scored higher than the "dismissing group" on CARS-aggression form, while "dismissing" participants scored significantly lower than "fearful" ones at both CARSaggression and CARS-victimization forms. 
Thus, our research points out the importance of participants' romantic attachment styles and their significant association with ITPV perpetration and victimization. In line with previous findings (e.g., He \& Tsang, 2014; Velotti et al., 2018), a dismissing attachment style seemed to be the most related to technological intimate partner violence (both perpetration and victimization). However, we also found that in the "victims" group, secure attachment styles were associated with the victims' ITPV perpetration. Moreover, in all three groups, ITPV victimization and perpetration are highly correlated, suggesting the potential double role of both victims and abusers. These results are in line with several other studies that already suggested the significant link between being a victim and becoming a perpetrator when discussing domestic violence in general (e.g., Bentovim, 2002). However, our findings point to the possibility of this cycle of abuse when also discussing technological intimate partner violence. Another potential explanation for the significant association between ITPV victimization and perpetration behavior might be related to the results suggested by Velotti et al. (2018) in their systematic review. The authors suggested that both forms of ITPV (abuse and victimization) might be explained through the need to self-regulate, generally felt by people with a dominant anxious and avoidant attachment style (which aligns with the present study data). Additionally, Doumas et al. (2008) also suggested that the "mispairing" of an avoidant male and an anxious female partner was associated with both male and female domestic violence. Though we could not measure this specific outcome in our study, given that only one of the two partners answered our questions, this may also be an interesting future research idea, primarily because these assumptions were not yet explored (to our knowledge) concerning ITPV.

We also explored the potential associations between partners' fidelity (or infidelity), relationship attachment styles, and ITPV. Our data resulted from the overall sample suggested that 1). generally, participants with a dismissing style cheated the most, while participants with an anxious dominant style cheated the least, and 2). participants with a dominant dismissing attachment style seemed to report the most frequent cheating episodes from their partners, while those with fearful dominant styles the least known infidelity behaviors from their partners. However, in the perpetrators' group, participants with a dismissing and fearful attachment style cheated the most, while participants with secure and anxious dominant styles cheated the least. In addition, participants with dismissing attachment styles seemed to report the most frequent cheating episodes from their partners in the victims' group, while those with a secure dominant style reported the least known infidelity behaviors from their partners. These results are significant in light of the previously suggested links between domestic violence abuse and victimization and partners' (in)fidelity (e.g., Pichon et al., 2020). Since the evidence related to infidelity and/or romantic jealousy and ITPV is relatively scarce, the present results might play an important role in future related research.
Our results suggested significant associations between ITPV - perpetration and victimization - and the research's primary variables. For example, in line with previous findings (e.g., Duerksen \& Woodin, 2019; Wachs et al., 2019), our data suggested that toxic disinhibition seemed to be significantly correlated with ITPV, a less surprising result that confirms our related assumptions. However, a more interesting result is related to the significant correlation between benign online disinhibition and ITPV perpetration (and not victimization) in the overall sample. The general effect of disinhibition may explain this specific result within maladaptive behaviors (Kyranides et al., 2017) and disinhibition as a psychological trait (i.e., "a dispositional liability toward maladaptive behaviors"; Delfin et al., 2020) and not necessarily related to one's online behavior (toxic or benign). However, to test these assumptions, future, more complex related investigations are needed.

Our assumption related to the significant link between moral disengagement and ITPV perpetration was confirmed: higher levels of moral disengagement were associated with higher ITPV perpetration levels. However, we did not expect to find the same pattern of results concerning ITPV victimization. A potential explanation for this specific association and the significant link between ITPV perpetration and victimization may be explicitly related to specific moral disengagement mechanisms, and the examples could be more various than we might think. For example, from an ITPV victims' perspective, one might think (using the advantageous comparison mechanism) that it is acceptable to look through their partner's e-mails since their partner installed a GPS tracking device on their car. Alternatively, when using the displacement or diffusion of responsibility mechanisms, ITPV victims might minimize their role in harmful actions or obscure personal agency by saying, "My partner was doing it, so I did it, too," or "I only used the spyware technology because he/she made me do it." Future studies might want to consider a more extensive analysis regarding the links between specific moral disengagement mechanisms and ITPV, using either an adapted version of the scale, i.e., items that would specifically measure ITPV-related moral disengagement mechanisms, or/ and adding open questions that would further be explored using mixed-method approaches (e.g., thematic analyses).

Our results suggested significant gender differences in all three groups related to toxic online disinhibition, i.e., male participants scored higher than females. These results seem to align with previous studies that suggested similar differences (e.g., Winstein \& Dannon, 2015) when exploring disinhibition in general (not necessarily online disinhibition). Also, in all samples, male participants seemed to be more morally disengaged than female participants, aligning with previous findings that suggested such differences (e.g., Bjärehed et al., 2020). Though in the overall sample, females seemed more stressed than males, in the perpetrators' group, male 
participants scored significantly higher than females at the stress measurements. However, correlational analyses cannot determine inference causality; therefore, we could not further assess whether stress caused ITPV perpetration or was actually a consequence of these abusive behaviors. More importantly, our data did not suggest any significant gender differences related to ITPV in the overall and victims' groups. However, in the ITPV-perpetrators group, we found that males had significantly higher scores than females on the CARS - victims' form. In other words, male perpetrators also experience significantly higher ITPV victimization compared to females.

Psychological distress, i.e., anxiety, depression, and stress, significantly correlated with participants' self-reported ITPV victimization and perpetration behaviors in the overall sample, as well as in the perpetrators' and victims' groups. More specifically, higher levels of distress were positively associated with higher levels of ITPV victimization and perpetration, in line with previous research (e.g., Kivisto, 2014; Riggs et al., 2000). Unfortunately, our data did not meet the necessary conditions to conduct multiple linear hierarchical regression (i.e., homoscedasticity and normality); therefore, we could not perform these analyses and assess the most efficient predictors of participants' proneness to technological intimate partner perpetration or victimization. Future studies, however, would benefit from exploring whether psychological distress is a significant predictor of ITPV or it is more a consequence of ITPV (or both). Finally, we could not perform any mediation and moderation analyses given our data characteristics (i.e., homoscedasticity and normality). Future studies might also benefit from exploring the potential mediating roles of online disinhibition and infidelity on the relationship between moral disengagement and ITPV perpetration and the potential moderating roles of dominant attachment styles, psychological distress, gender, and age.

The COVID-19 had a significant impact on our lives, relationships, online behaviors, and an increasing number of studies that had already suggested its negative influence on the enhancement of domestic violence (e.g., Evans et al., 2020; Viero et al., 2021). Our results also suggested that, in the overall sample, almost $20 \%$ of participants who were able to compare ITPV behaviors from the last six months with behaviors before the pandemic confirmed that ITPV perpetration and victimization escalated during the pandemic. These percentages were even higher in the victims' group when assessing the pandemic's impact on ITPV victimization. Though these numbers might seem less important, they indicated that 1 in 4 potential victims of ITPV reported the harmful effect of the COVID-19 pandemic concerning technological intimate partner abuse. This specific result aligns with previous studies highlighting the pandemic's negative impact concerning domestic violence and the need for increased victim-support programs.
Several limitations need to be mentioned concerning the present research. First, our study is cross-sectional, using a convenient sample and self-reported measures, which lower its generalizability. Second, we did not assess the potential impact of cultural beliefs and competence related to and intimate partner abuse and other potentially related factors (e.g., sexism), and previous research highlighted their significant roles when exploring domestic violence (e.g., Çalıkoglu et al., 2018; Tonsing, 2016). Third, additional and/or specific COVID-19 related factors might have contributed to enhanced ITPV (e.g., length of quarantine/home confinement; Mazza et al., 2020), which might be explored in further research.

One of the most important limitations is related to how we created the "victims" and "perpetrators" groups. As we already mentioned, it is important to consider that the way we differentiated these groups, and that lower scores on ITPV perpetration, for example, might have indicated that one of the described ITPV behaviors happened once. Previous research that assessed ITPV using the CARS scale (e.g., Duerksen and Wooding, 2019) used the total score that assessed the perpetration of ITPV. Though the rationale behind the cut-off score that we used was based on the scores that would indicate at least one possible ITPV experience that happened at least once in the last six months, this specific arbitrary cut-off point raises the need for further exploratory related studies. Moreover, these groups are not mutually exclusive. For example, previous research has already pointed out the bidirectional nature of cyber aggression, i.e., cybervictims who subsequently engage in cyber-perpetrating behaviors or cyber-aggressors who also experience cyber victimization (e.g., Paat et al., 2019). Thus, future studies might benefit from exploring the relationship between our primary variables of research, ITPV perpetration, and ITPV victimization by using a similar cut-off approach and adding additional insight into the data analysis, i.e., exploring these relationships the "perpetrators and victims" group, separately. We pointed out that our results suggested a high correlation between ITPV victimization and perpetration, highlighting the cycle of abuse when also discussing ITPV. Thus, this further research approach might indicate a different relationship dynamic between ITPV, online disinhibition, dominant attachment patterns, and moral disengagement. Furthermore, future studies might also benefit from exploring the associated factors of ITPV using both similar and distinct cut-off approaches to understand these patterns.

Another potential limitation of our study is related to the online disinhibition framework, as it was characterized by Suler (2004), on which Udris's scale (2014), the one that we used, was built on. Given that this specific model of online disinhibition (i.e., Suler's model) was conceptualized before the social media era, it might be limited by the recent changes in the ways people now communicate and socialize within the online environment. Though the scale developed by Udris in 
2014 altered the questions' wording so that the disinhibition assessment applied to all technology use (i.e., the scale was updated to the more modern technological means, rather than solely Internet usage), as Duerksen and Woodin also mention (Duerksen \& Woodin, 2019), future related research is needed to explore this potential limitation. Finally, another potential limitation and an interesting research direction is related to the fact that we did not measure ITPV using a dyadic approach, i.e., both partners' perspectives, but only used unilateral reports. As Watkins and their collaborators also suggested (2016), future related research might benefit from acquiring both partners' reports of perpetration and victimization, further contributing to a more comprehensive examination of ITPV concordance among the partners.

First, the number of studies that had yet explored technological intimate partner violence is relatively scarce. However, despite these limitations, we consider that the present result might have a theoretical and a practical contribution to the research related to intimate partner abuse. To our knowledge, this might be 1) the first research conducted using a Romanian sample; 2) the first study to explore the links between ITPV both forms - victimization and perpetration, and moral disengQagement (in addition to the other variables); and 3) the first study to assess the direct impact of the Covid-19 pandemic on ITPV. Therefore, our results might be significant for their theoretical contribution, adding to the existing related literature.

Furthermore, our results might also be important through a more practical perspective on domestic violence prevention and intervention programs and strategies, especially during the pandemic. For example, given the significant correlations found between ITPV perpetration and victimization and psychological distress, free, therapeutical couples' programs might be designed to reduce depression, anxiety, and stress, already enhanced by the pandemic context. Other prevention efforts might focus on acknowledging and recognizing ITPV, given that cultural factors and several other related contextual factors might contribute to unreported such domestic violence forms, especially among men. Violence prevention addresses a collective responsibility of community members and community services. We consider that the prevention and intervention programs addressing all forms of domestic violence, with a focus on ITPV, should combine the efforts made by the judicial system (e.g., the Police), the educational structure (e.g., basic school programs and university courses), the medical institutions and representatives (e.g., family and community doctors), and the religious organization, especially in such religious countries as Romania is. For example, given that our findings highlighted the significant relationship between ITPV perpetration and moral disengagement, in line with other previous studies that linked unethical relational behavior and domestic violence (Clemente et al., 2019; CuadradoGordillo et al., 2020), we consider that educational and community-based intervention and prevention programs should focus on reducing the primary moral disengagement mechanisms underlying such violent behavior. One practical intervention in this regard might be focused on reducing and, finally, eliminating cognitive processing that generally leads to dehumanization, diffusion, and displacement of responsibility, or blaming the victims of ITPV, as other studies previously suggested when exploring the mechanisms underlying similar conducts in cyber-aggression (e.g., Falla et al. 2021; Wang \& Ngai, 2020).

More importantly, our findings might be all the more important within the social and cultural context of Romania, especially when considering the high prevalence of the morally disengaged perspective on domestic violence (i.e., considering domestic violence as "normal" and justified behavior; BBC, 2017), and the recent case related to cyber-domestic violence that brought the country the European Court of Human Rights conviction in 2020. Our results suggest the need for more practical, integrated, and community-based interventions to prevent and diminish all forms of domestic violence, ITPV included, all the more within the Covid-19 domestic violence exacerbation in Romania (Socea et al., 2020), as well as worldwide (Piquero et al., 2021).

\section{Declarations}

Ethics Statement This study's protocol was designed in concordance with ethical requirements specific to the Faculty of Psychology and Educational Sciences," Alexandru Ioan Cuza" University (Iasi, Romania), before beginning the study and supervised by Alexandra Maftei. All participants voluntarily participated in the study and gave written informed consent following the Declaration of Helsinki and the national laws from Romania regarding ethical conduct in scientific research, technological development, and innovation.

Conflict of Interest The authors declare that they have no known competing financial interests or personal relationships that could have influenced the work reported in this paper.

The authors declare no financial interests/personal relationships, which may be considered as potential competing interests.

\section{References}

Bandura, A. (2002). Selective moral disengagement in the exercise of moral agency. Journal of Moral Education, 31(2), 101-119. https://doi.org/10.1080/0305724022014322

Bandura, A., Barbaranelli, C., Caprara, G. V., \& Pastorelli, C. (1996). Mechanisms of moral disengagement in the exercise of moral agency. Journal of Personality and Social Psychology, 71, 364-374

Baym, N. (2010). Personal connections in the digital age. Polity Press

BBC (2017). Romania criticised over domestic violence 'failures'. https:// www.bbc.com/news/world-europe-40010890

Bennett, D. C., Guran, E. L., Ramos, M. C., \& Margolin, G. (2011). College students' electronic victimization in friendships and dating relationships: Anticipated distress and associations with risky 
behaviors. Violence and Victims, 26(4), 410-429. https://doi.org/10. 1891/0886-6708.26.4.410

Bentovim, A. (2002). Preventing sexually abused young people from becoming abusers, and treating the victimization experiences of young people who offend sexually. Child Abuse \& Neglect, 26(67), 661-678. https://doi.org/10.1016/s0145-2134(02)00340-x

Bjärehed, M., Thornberg, R., Wänström, L., \& Gini, G. (2020). Mechanisms of moral disengagement and their associations with indirect bullying, direct bullying, and pro-aggressive bystander behavior. The Journal of Early Adolescence, 40(1), 28-55. https://doi. org/10.1177/0272431618824745

Blanco, A., Davies-Rubio, A., De la Corte, L., \& Mirón, L. (2020). Violent extremism and moral disengagement: A study of Colombian armed groups. Journal of interpersonal violence, 886260520913643. Advance online publication. https://doi.org/10. $1177 / 0886260520913643$

Bond, S. B., \& Bond, M. (2004). Attachment styles and violence within couples. The Journal of Nervous and Mental Disease, 192(12), 857863. https://doi.org/10.1097/01.nmd.0000146879.33957.ec

Bowlby, J. (1982). Attachment and loss (Vol. I: Attachment). Basic Books.

Brubacher, L. (2018). Attachment injury resolution model in emotionally focused therapy. In J. Lebow, A. Chambers, \& D. Breunlin (Eds.), Encyclopedia of couple and family therapy. Springer. https://doi. org/10.1007/978-3-319-15877-8_903-1

Burke, S. C., Wallen, M., Vail-Smith, K., \& Knox, D. (2011). Using technology to control intimate partners: An exploratory study of college undergraduates. Computers in Human Behavior, 27(3), 1162-1167. https://doi.org/10.1016/j.chb.2010.12.010

Çalıkoglu, E. O., Aras, A., Hamza, M., Aydin, A., Nacakgedigi, O., \& Koga, P. M. (2018). Sexism, attitudes, and behaviors towards violence against women in medical emergency services workers in Erzurum, Turkey. Global Health Action, 11(1), 1524541. https:// doi.org/10.1080/16549716.2018.1524541

Cheung, J., Tsoi, V., Wong, K., \& Chung, R. Y. (2019). Abuse and depression among Filipino foreign domestic helpers. A crosssectional survey in Hong Kong. Public health, 166, 121-127. https://doi.org/10.1016/j.puhe.2018.09.020

Chisholm, C. A., Bullock, L., \& Ferguson 2nd, J. (2017). Intimate partner violence and pregnancy: Epidemiology and impact. American Journal of Obstetrics and Gynecology, 217(2), 141-144. https:// doi.org/10.1016/j.ajog.2017.05.042

Chisholm, J. F. (2006). Cyberspace violence against girls and adolescent females. In F. L. Denmark, H. H. Krauss, E. Halpern, \& J. A. Sechzer (Eds.), Violence and exploitation against women and girls (pp. 74-89). Blackwell.

Clemente, M., Espinosa, P., \& Padilla, D. (2019). Moral disengagement and willingness to behave unethically against ex-partner in a child custody dispute. PLoS One, 14(3), e0213662. https://doi.org/10. 1371/journal.pone. 0213662

Clevenger, S., \& Gilliam, M. (2020). Intimate partner violence and the internet: Perspectives. In T. Holt \& A. Bossler (Eds.), The Palgrave handbook of international cybercrime and Cyberdeviance. Palgrave Macmillan. https://doi.org/10.1007/978-3-319-78440-3_58

Cuadrado-Gordillo, I., Fernández-Antelo, I., \& Martín-Mora Parra, G. (2020). Moral disengagement as a moderating factor in the relationship between the perception of dating violence and victimization. International Journal of Environmental Research and Public Health, 17(14), 5164. https://doi.org/10.3390/ijerph17145164

D’Urso, G., Petruccelli, I., Costantino, V., Zappulla, C., \& Pace, U. (2018). The role of moral disengagement and cognitive distortions toward children among sex offenders. Psychiatry Psychology and Law, 26(3), 414-422. https://doi.org/10.1080/13218719.2018. 1506718

Delfin, C., Ruzich, E., Wallinius, M., Björnsdotter, M., \& Andiné, P. (2020). Trait disinhibition and NoGo event-related potentials in violent mentally disordered offenders and healthy controls. Frontiers in Psychiatry, 11, 577491. https://doi.org/10.3389/fpsyt. 2020.577491

Desmarais, S. L., Reeves, K. A., Nicholls, T. L., Telford, R. P., \& Fiebert, M. S. (2012). Prevalence of physical violence in intimate relationships, part 2: Rates of male and female perpetration. Partner Abuse, 3(2), 170-198. https://doi.org/10.1891/1946-6560.3.2.170

Dick, R. N., McCauley, H. L., Jones, K. A., Tancredi, D. J., Goldstein, S., Blackburn, S., . . Miller, E. (2014). Cyber dating abuse among teens using school-based health centers. Pediatrics, 134(6), e1560-e1567. https://doi.org/10.1542/peds.2014-0537.

Doumas, D. M., Pearson, C. L., Elgin, J. E., \& McKinley, L. L. (2008). Adult attachment as a risk factor for intimate partner violence: The "mispairing" of partners' attachment styles. Journal of Interpersonal Violence, 23(5), 616-634. https://doi.org/10.1177/ 0886260507313526

Duerksen, K. N., \& Woodin, E. M. (2019). Technological intimate partner violence: Exploring technology-related perpetration factors and overlap with in-person intimate partner violence. Computers in Human Behavior, 98, 223-231. https://doi.org/10.1016/j.chb.2019. 05.001

Evans, M. L., Lindauer, M., \& Farrell, M. E. (2020). A pandemic within a pandemic - intimate partner violence during Covid-19. The New England Journal of Medicine, 383(24), 2302-2304. https://doi.org/ 10.1056/NEJMp2024046

Felson, R. B., Messner, S. F., Hoskin, A. W., \& Deane, G. (2002). Reasons for Reporting and Not Reporting Domestic Violence to the Police. Criminology, 40(3), 617-647

Freed, D., Palmer, J., Minchala, D., Levy, K., Ristenpart, T., \& Dell, N. (2017). Digital Technologies and Intimate Partner Violence: A Qualitative Analysis with Multiple Stakeholders. Proceedings of the ACM on Human-Computer Interaction, 1, 1-22. https://doi. org $/ 10.1145 / 3134681$

Goldenson, J., Geffner, R., Foster, S. L., \& Clipson, C. R. (2007). Female domestic violence offenders: Their attachment security, trauma symptoms, and personality organization. Violence and Victims, 22(5), 532-545. https://doi.org/10.1891/088667007782312186

He, S., \& Tsang, S. (2014). Male partners' attachment styles as predictors of women's coerced first sexual intercourse in Chinese college students' dating relationships. Violence and Victims, 29(5), 771-783. https://doi.org/10.1891/0886-6708.vv-d-12-00116

Hellevik, P. M. (2019). Teenagers' personal accounts of experiences with digital intimate partner violence and abuse. Computers in Human Behavior, 92, 178-187. https://doi.org/10.1016/j.chb.2018.11.019

Hinduja, S., \& Patchin, J. W. (2009). Bullying beyond theschoolyard: Preventing and responding to cyberbullying. Sage Publications (CorwinPress)

Huecker, M. R., King, K. C., Jordan, G. A., \& Smock, W. (2021). Domestic violence. In StatPearls. StatPearls Publishing.

Johnson, S. M. (2006). Attachment theory: A guide for couple therapy. In S. M. Johnson \& V. E. Whiffen (Eds.), Attachment processes in couple and family therapy (pp. 124-143). Guilford

Johnson, S. M., Makinen, J. A., \& Millikin, J. W. (2001). Attachment injuries in couple relationships: A new perspective on impasses in couples therapy. Journal of Marital and Family Therapy, 27(2), 145-155. https://doi.org/10.1111/j.1752-0606.2001.tb01152.x

Kivisto, A. J. (2014). Abandonment and engulfment: A bimodal classification of anxiety in domestic violence perpetrators. Aggression and Violent Behavior, 19(3), 200-206. https://doi.org/10.1016/j.avb. 2014.04.005

Kolbe, V., \& Büttner, A. (2020). Domestic violence against menprevalence and risk factors. Deutsches Arzteblatt International, 117(31-32), 534-541. https://doi.org/10.3238/arztebl.2020.0534

Kyranides, M. N., Fanti, K. A., Sikki, M., \& Patrick, C. J. (2017). Triarchic dimensions of psychopathy in young adulthood: Associations with clinical and physiological measures after 
accounting for adolescent psychopathic traits. Personality Disorders, 8(2), 140-149. https://doi.org/10.1037/per0000193

Lafta, R. K. (2008). Intimate-partner violence and women's health. The Lancet, 371(9619), 1140-1142. https://doi.org/10.1016/s01406736(08)60499-7

Lovibond, P. F., \& Lovibond, S. H. (1995). The structure of negative emotional states: Comparison of the Depression Anxiety Stress Scales (DASS) with the Beck Depression and Anxiety Inventories. Behaviour Research and Therapy, 33(3), 335-343. https://doi.org/ 10.1016/0005-7967(94)00075-U

Lutgendorf, M. A. (2019). Intimate partner violence and Women's health. Obstetrics and Gynecology, 134(3), 470-480. https://doi.org/10. 1097/AOG.0000000000003326

Maftei, A., \& Holman, A.-C. (2020). Predictors of homophobia in a sample of Romanian young adults: age, gender, spirituality, attachment styles, and moral disengagement. Psychology \& Sexuality. https://doi.org/10.1080/19419899.2020.1726435

Marganski, A., \& Melander, L. (2015). Intimate partner violence victimization in the cyber and real world: Examining the extent of cyber aggression experiences and its association with in-person dating violence. Journal of Interpersonal Violence, 33(7), 1071-1095. https://doi.org/10.1177/0886260515614283

Mazza, M., Marano, G., Lai, C., Janiri, L., \& Sani, G. (2020). Danger in danger: Interpersonal violence during COVID-19 quarantine. Psychiatry Research, 289, 113046. https://doi.org/10.1016/j. psychres.2020.113046

McFarlane, J., Campbell, J. C., \& Watson, K. (2002). Intimate partner stalking and femicide: Urgent implications for women's safety. Behavioral Sciences \& the Law, 20, 51-68.

Melander, L. A. (2010). College students' perceptions of intimate partner cyber harassment. Cyberpsychology, Behavior and Social Networking, 13, 263-268.

Moore, C. (2015). Moral disengagement. Current Opinion in Psychology, 6, 199-204. https://doi.org/10.1016/j.copsyc.2015.07. 018

Muller, H. J., Desmarais, S. L., \& Hamel, J. M. (2009). Do Judicial Responses to Restraining Order Requests Discriminate Against Male Victims of Domestic Violence? Journal of Family Violence, 24, 625-637. https://doi.org/10.1007/s10896-009-9261-4

Nacar, G., Taşhan, S. T., \& Bekar, M. (2021). Adaptation of the cyber aggression in relationships scale toTurkish: A validity and reliability study. Perspectives in Psychiatric Care, 57, 253-262. https://doi. org/10.1111/ppc.12556

Nemeth, J. M., Bonomi, A. E., Lee, M. A., \& Ludwin, J. M. (2012). Sexual infidelity as trigger for intimate partner violence. Journal of Women's Health, 21(9), 942-949. https://doi.org/10.1089/jwh. 2011.3328

Paat, Y. F., Markham, C., \& Peskin, M. (2019). Psycho-Emotional Violence, Its Association, Co-Occurrence, and Bidirectionality with Cyber, Physical and Sexual Violence. Journal of Child \& Adolescent Trauma, 13(4), 365-380. https://doi.org/10.1007/ s40653-019-00283-z

Paciello, M., Fida, R., Tramontano, C., Lupinetti, C., \& Caprara, G. V. (2008). Stability and change of moral disengagement and its impact on aggression and violence in late adolescence. Child development, 79(5), 1288-1309. https://doi.org/10.1111/j.1467-8624.2008. 01189.x

Pichon, M., Treves-Kagan, S., Stern, E., Kyegombe, N., Stöckl, H., \& Buller, A. M. (2020). A mixed-methods systematic review: Infidelity, romantic jealousy and intimate partner violence against women. International Journal of Environmental Research and Public Health, 17(16), 5682. https://doi.org/10.3390/ ijerph17165682

Riggs, D. S., Caulfield, M. B., \& Street, A. E. (2000). Risk for domestic violence: Factors associated with perpetration and victimization. Journal of Clinical Psychology, 56(10), 1289-1316. https:// doi.org/10.1002/1097-4679(200010)56:10<1289::aidjclp4 $>3.0 . \mathrm{co} ; 2-\mathrm{Z}$

Risser, S., \& Eckert, K. (2016). Investigating the relationships between antisocial behaviors, psychopathic traits, and moral disengagement. International Journal of Law and Psychiatry, 45, 70-74. https://doi. org/10.1016/j.ijlp.2016.02.012

Runions, K. C., \& Bak, M. (2015). Online moral disengagement, cyberbullying, and cyber-aggression. Cyberpsychology, Behavior and Social Networking, 18(7), 400-405. https://doi.org/10.1089/ cyber.2014.0670

Sánchez-Jiménez, V., \& Muñoz-Fernández, N. (2021). When are sexist attitudes risk factors for dating aggression? The role of moral disengagement in Spanish adolescents. International Journal of Environmental Research and Public Health, 18(4), 1947. https:// doi.org/10.3390/ijerph18041947

Scott, A. J., Lloyd, R., \& Gavin, J. (2010). The influence of prior relationship on perceptions of stalking in the United Kingdom and Australia. Criminal Justice and Behavior, 37, 1185-1194.

Sediri, S., Zgueb, Y., Ouanes, S., Ouali, U., Bourgou, S., Jomli, R., \& Nacef, F. (2020). Women's mental health: acute impact of COVID19 pandemic on domestic violence. Archives of women's mental health, 23(6), 749-756. https://doi.org/10.1007/s00737-02001082-4

Shimizu, A. (2013). Recent Developments Domestic Violence in the Digital Age: Towards the Creation of a Comprehensive Cyberstalking Statute. Berkeley Journal of Gender, Law \& Justice, 28(1), 1125573. https://doi.org/10.15779/Z38H708030

Sijtsema, J. J., Garofalo, C., Jansen, K., \& Klimstra, T. A. (2019). Disengaging from evil: Longitudinal associations between the dark triad, moral disengagement, and antisocial behavior in adolescence. Journal of Abnormal Child Psychology, 47(8), 1351-1365. https:// doi.org/10.1007/s10802-019-00519-4

Slootmaeckers, J., \& Migerode, L. (2018). Fighting for connection: Patterns of intimate partner violence. Journal of Couple \& Relationship Therapy, 17(4), 294-312. https://doi.org/10.1080/ 15332691.2018.1433568

Slootmaeckers, J., \& Migerode, L. (2020). EFT and intimate partner violence: A roadmap to De-escalating violent patterns. Family Process, 59(3), 328-345. https://doi.org/10.1111/FAMP.12468

Socea, B., Bogaciu, C., Nica, A. A., Smaranda, A. C., Ciobotaru, V. P., Crăciun, R. I., et al. (2020). Politrauma during Covid-19 pandemic: an increasing incidence of domestic violence. Romanian Journal ofEmergency Surgery, 2(1), 20-24. https://doi.org/10.33695/rojes. $\mathrm{v} 2 \mathrm{i} 1.20$

Spencer, C. M., Keilhotltz, B. M., \& Stith, S. M. (2021). The association between attachment styles and physical intimate partner violence perpetration and victimization: A Meta-analysis. Family Process, 60(1), 270-284. https://doi.org/10.1111/famp.12545

Southworth, C., Finn, J., Dawson, S., Fraser, C., \& Tucker, S. (2007). Intimate partner violence, technology, and stalking. Violence Against Women, 13(8), 842-856. https://doi.org/10.1177/ 1077801207302045

Straus, M. A. (2009). Gender symmetry in partner violence: Evidence and implications for prevention and treatment. In D. J. Whitaker \& J. R. Lutzker (Eds.), Preventing partner violence: Research and evidence-based intervention strategies (pp. 245-271). American Psychological Association. https://doi.org/10.1037/11873-011

Suler, J. (2004). The online disinhibition effect. Cyberpsychology \& Behavior, 7(3), 321-326. https://doi.org/10.1089/ 1094931041291295 https://www.bbc.com/news/world-europe40010890

Taylor, S., \& Xia, Y. (2018). Cyber partner abuse: A systematic review. Violence and Victims, 33(6), 983-1011. https://doi.org/10.1891/ 0886-6708.33.6.983

Teng, Z., Bear, G. G., Yang, C., Nie, Q., \& Guo, C. (2020). Moral disengagement and bullying perpetration: A longitudinal study of 
the moderating effect of school climate. School psychology (Washington, D.C.), 35(1), 99-109. https://doi.org/10.1037/ spq0000348

Tonsing, J. C. (2016). Domestic violence: Intersection of culture, gender and context. Journal of immigrant and Minority Health, 18(2), 442446. https://doi.org/10.1007/s10903-015-0193-1

Toplu-Demirtaș, E., May, R. W., Seibert, G. S., \& Fincham, F. D. (2020). Does cyber dating abuse victimization increase depressive symptoms or vice versa? Journal of interpersonal violence, 886260520984261 . Advance online publication. https://doi.org/10. $1177 / 0886260520984261$

Udris, R. (2014). Cyberbullying among high school students in Japan: Development and validation of the Online Disinhibition Scale. Computers in Human Behavior, 41, 253-261. https://doi.org/10. 1016/j.chb.2014.09.036

Van Ouytsel, J., Ponnet, K., Walrave, M., \& Temple, J. R. (2016). Adolescent cyber dating abuse victimization and its associations with substance use, and sexual behaviors. Public Health, 135, 147-151. https://doi.org/10.1016/j.puhe.2016.02.011

Velotti, P., Beomonte Zobel, S., Rogier, G., \& Tambelli, R. (2018). Exploring relationships: A systematic review on intimate partner violence and attachment. Frontiers in Psychology, 9, 1166. https:// doi.org/10.3389/fpsyg.2018.01166

Viero, A., Barbara, G., Montisci, M., Kustermann, K., \& Cattaneo, C. (2021). Violence against women in the Covid-19 pandemic: A review of the literature and a call for shared strategies to tackle health and social emergencies. Forensic Science International, 319, 110650. https://doi.org/10.1016/j.forsciint.2020.110650

Wachs, S., Wright, M. F., \& Vazsonyi, A. T. (2019). Understanding the overlap between cyberbullying and cyberhate perpetration: Moderating effects of toxic online disinhibition. Criminal Behaviour and Mental Health, 29(3), 179-188. https://doi.org/10. 1002/cbm.2116
Wang, X., Yang, J., Wang, P., Zhang, Y., Li, B., Xie, X., \& Lei, L. (2020). Deviant peer affiliation and bullying perpetration in adolescents: The mediating role of moral disengagement and the moderating role of moral identity. The Journal of Psychology, 154(3), 199213. https://doi.org/10.1080/00223980.2019.1696733

Watkins, L. E., Schumacher, J. A., \& Coffey, S. F. (2016). A Preliminary Investigation of the Relationship between Emotion Dysregulation and Partner Violence Perpetration Among Individuals with PTSD and Alcohol Dependence. Journal of aggression, maltreatment \& trauma, 25(3), 305-314. https://doi.org/10.1080/10926771.2015. 1129657

Wolford-Clevenger, C., Zapor, H., Brasfield, H., Febres, J., Elmquist, J., Brem, M., Shorey, R. C., \& Stuart, G. L. (2016). An examination of the partner cyber-abuse questionnaire in a college student sample. Psychology of Violence, 6(1), 156-162. https://doi.org/10.1037/ a0039442

Woodlock, D. (2016). The abuse of Technology in Domestic Violence and Stalking. Violence Against Women, 23(5), 584-602. https://doi. org/10.1177/1077801216646277

World Health Organization (WHO) (2017). Violence against women. https://www.who.int/health-topics/violence-against-women\#tab= tab_1

Zweig, J. M., Dank, M., Yahner, J., \& Lachman, P. (2013). The rate of cyber dating abuse among teens and how it relates to other forms of teen dating violence. Journal of Youth and Adolescence, 42(7), 1063-1077. https://doi.org/10.1007/s10964-013-9922-8

Zweig, J. M., Lachman, P., Yahner, J., \& Dank, M. (2014). Correlates of cyber dating abuse among teens. Journal of youth and adolescence, 43(8), 1306-1321. https://doi.org/10.1007/s10964-013-0047-x

Publisher's Note Springer Nature remains neutral with regard to jurisdictional claims in published maps and institutional affiliations. 